\title{
Saúde mental do policial militar: Relações interpessoais e estresse no exercício profissional
}

\author{
Mental health of the military police officer: Interpersonal relations and stress within the \\ professional practice
}

\footnotetext{
${ }^{[a]}$ Psicólogo, Doutor em Psicologia pela Universidade São Francisco (USF), professor da Universidade Federal de Goiás no Campus Catalão - UFG/CAC, Catalão, GO - Brasil, e-mail: gleibercouto@yahoo.com.br

${ }^{[\mathrm{b}]}$ Bacharel em Ciências Militares (APMMG), Poços de Caldas, MG - Brasil, e-mail: earaujos@click21.com.br

${ }^{\text {[c] }}$ Psicólogo, Doutor em Ciências do Comportamento pela Universidade de Brasília (UnB), professor adjunto da Universidade Federal de Goiás (UFG), Catalão, GO - Brasil, e-mail: profandrevs@hotmail.com

${ }^{\text {[d] }}$ Doutora em Enfermagem e Mestre em Enfermagem Psiquiátrica pela Escola de Enfermagem da Universidade de São Paulo (USP), professora adjunta da Universidade Federal de Goiás (UFG), Catalão, GO - Brasil, e-mail: roselmalucchese@hotmail.com
}

Recebido: 05/04/2011 Received: 04/05/2011

Aprovado: 21/06/2011 Approved: 06/21/2011

\author{
Gleiber Couto ${ }^{[a]}$, Emerson de Araújo Garro Brito ${ }^{[b]}$, André Vasconcelos-Silva ${ }^{[\mathrm{c}]}$, Roselma Lucchese ${ }^{[\mathrm{dd}]}$
}

\section{Resumo}

O objetivo deste trabalho foi investigar características da saúde mental do policial militar. Para tanto foi investigada a percepção do policial sobre variáveis de estresse e características de relacionamento interpessoal em grupos divididos pelo tempo de exercício profissional. Participaram 325 alunos dos cursos de formação de oficiais da Policia Militar de um estado brasileiro com idades entre 18 e 49 anos ( $M=31,9$ e $D P=8,3)$, sendo 90,8\% dos sujeitos do sexo masculino (297). 0 tempo de serviço como policial variou entre 2 meses e 23,75 anos $(M=10,56$ e DP=8,54). Os sujeitos responderam ao Inventário de Sintomas de Estresse de Lipp (ISSL) e ao Checklist de Relações Interpessoais - Revisado (CLOIT-R). Os resultados apontaram sintomas de estresse em 55,9\% da amostra. Apontaram também o efeito positivo do tempo de carreira na saúde dos policiais, primeiro pela redução dos sintomas de estresse e de características interpessoais negativas ao longo da carreira, e segundo pelo aumento correspondente entre as características interpessoais positivas e tempo de carreira. Concluiu-se que novos estudos são necessários para ampliar as informações sobre o tema e foi recomendado que as atenções institucionais e as eventuais medidas profiláticas sejam direcionadas para o início da carreira policial.

Palavras-chave: Saúde do trabalhador. Estresse psicológico. Relações interpessoais. Polícia. Atividades militares.

\section{Abstract}

This paper aims to investigate mental health features of the military policeman, for thisn purpose the effect of years of professional practice under stress and interpersonal relationship characteristics of military policemen were analysed. There were 325 students from the training courses of Military Police Officers of a Brazilian state attended, with ages ranging from 18 to 49 years old ( $M=31.9, D P=8.3), 90.8 \%$ of the subjects were male (297). The time of service as a police officer ranged from 2 months to 23.75 years $(M=10.56, D P=8.54)$. The subjects answered Lipp's Inventory of Stress Symptoms (ASSI) and the Revised Checklist of Interpersonal Relations (CLOIT-R). The results showed stress symptoms in 55.9\% of the sampled subjects. They also 
pointed out the positive effect of career time of work for the health of police officers, first for the reduction in the stress symptoms and negative interpersonal characteristics throughout their careers, and second for the corresponding increase of the positive interpersonal characteristics and career lenght. It was concluded that further studies are needed to increase the information about the topic and it was recommended that institutional attention and possible preventive measures are directed to the top of the career as police officers..

Keywords: Occupational Health. Psychological stress. Interpersonal relations. Police. Military activities.

\section{Introdução}

Uma das maiores preocupações da sociedade contemporânea é a segurança do cidadão diante da crescente violência, sobretudo nos grandes centros urbanos (Silva \& Vieira, 2008). Esta é uma condição que convida à reflexão acerca da profissão do policial, que tem como norte de suas atividades a segurança pública. Contudo, este estudo parte do pressuposto de que a atividade profissional dos policiais os coloca cotidianamente em situação de estresse, pela frequência com que lida com a agressividade e morte, em concordância com dados apresentados na literatura sobre o tema (Costa, Accioly, Oliveira \& Maia, 2007; Dela Coleta \& Dela Coleta, 2008).

Portanto os policiais têm suas condições laborais, ambientais fundamentadas pelo risco. 0 risco entendido como o perigo, o local e a frequência da ocorrência de fatalidades, tudo associado a ousadia e afronta que são inerentes à atividade policial diante de tais acontecimentos. Em grande parte das situações, o policial vê a definição de suas ações e de seu trabalho, calçado na surpresa dos acontecimentos e no curto espaço de tempo para delinear sua ação. É preciso, rapidamente, reconhecer expressões faciais, movimentos corporais, humor e as intenções de outras pessoas ou de outros organismos que estão ao nosso redor. Segundo Ornstein (1998), essa capacidade de avaliar as situações imediatas formam a base da inteligência social. Além desta característica, o estudo de Minayo, Souza e Constantino (2007) revelou que policiais que sofreram elevado risco na prática profissional foram os que mais experienciaram violência, como ferimento por projétil de arma de fogo ou por arma branca, agressão física, violência sexual, tentativa de suicídio e tentativa de homicídio.
Essa excessiva exposição a riscos e violência, juntamente com as cobranças de eficiência da sociedade e as precárias condições de trabalho no âmbito nacional, constituem fenômenos que atribuem ao policial um status de destaque entre os servidores que mais sofrem de estresse (Souza Franco, Meireles, Ferreira \& Santos 2007). Não o bastante, também lhe é atribuída a competência de tomar decisões e intervir em situações complexas, envolvendo questões de vida humana em um contexto de forte tensão (Costa et al., 2007), em uma sociedade que apresenta um aumento crescente nos dados de violência e criminalidade com respostas de políticas públicas empobrecidas no âmbito social e de infraestrutura (Silva \& Vieira, 2008).

Os fatores estressantes a que o policial é submetido no exercício de sua profissão podem então, ser compreendidos como um processo de sofrimento psíquico que interfere em suas respostas às demandas laborais (Souza et al., 2007). Além disso, o estresse interfere prejudicando a qualidade das relações interpessoais, gerando um mecanismo de retro-alimentação negativa, ou seja, a qualidade das relações interpessoais é indicador da quantidade de estresse presente na vida das pessoas e também contribui como importante fator gerador do mesmo. Dessa forma, queda na capacidade de produzir interações satisfatórias, tanto na dimensão pessoal quanto profissional, possui estreitas relações com qualidade de vida e saúde dos indivíduos (Lipp, 1996; Minayo \& Souza, 2003).

Sendo assim, estudar questões acerca do estresse e do relacionamento interpessoal entre os policiais é primordial para a compreensão da saúde mental dessa categoria, e seus resultados podem apontar melhorias a serem implementadas na formação e educação permanente destes. Tendo em vista que as reflexões e pesquisas acerca da saúde 
do trabalhador policial são escassas, conforme pesquisa que descreveu o perfil do que foi publicado na área de saúde do trabalhador no século XXI e apontou que a profissão menos estudada entre os trabalhos analisados foi a dos militares, com 2,35\% do total (Bezerra \& Neves, 2010).

No Brasil, as limitações desses estudos podem ser decorrentes de dois fatores essenciais, o primeiro seria a influência histórica do regime militar que ainda silencia os fenômenos que envolvem as atividades práticas destes servidores; o segundo seria os rígidos princípios de hierarquia e disciplina que são a base da organização burocrática da polícia ainda enraizada no século XIX, revitalizando a lógica de preservação de interesses da corporação, inviabilizando profundas mudanças que acompanhem a dinâmica da sociedade (Silva \& Vieira, 2008).

Também considera-se nesta discussão o princípio básico apresentado no VIII Congresso das Nações Unidas para Prevenção do Crime e o Tratamento de Delinquentes - Consenso de 7 de setembro/1990 ONU -It.21 - "Los gobiernos y sectores responsables por la aplicación de la ley, tendran que proporcionar orientación en salud a todos los encargados de la Seguridad Publica" (ONU, 1990). Princípio que fundamenta a orientação quanto a importância de uma investigação sobre as condições de saúde, especialmente saúde mental, no exercício do policiamento operacional e aponta a responsabilidade do Estado nesse processo.

Alguns estudos nacionais investigaram fatores ligados à saúde mental de policiais (Silveira et al., 2005), como também a relevância de variáveis psicológicas para a previsão de comportamento desviante (Brito \& Goulart , 2005). Esses trabalhos demonstram o interesse e a relevância do estudo sobre variáveis psicológicas relacionadas à saúde e ao bom desempenho profissional dos policiais. Um estudo brasileiro, com o objetivo em diagnosticar a ocorrência e a fase de estresse e de determinar a prevalência de sintomas físicos e mentais em policiais militares, contou com a participação de 264 indivíduos. Os resultados apontaram que um total de $47,4 \%$ da amostra apresentou sintomatologia de estresse, destes 3,4\% encontravam-se na fase de alerta, 39,8\% na fase de resistência, 3,8\% na fase de quase-exaustão e $0,4 \%$ na fase de exaustão. Sintomas psicológicos foram registrados em $76,0 \%$ dos policiais com estresse, e sintomas físicos, em $24,0 \%$. Das variáveis investigadas, a única que apresentou relação com estresse foi o sexo sendo as mulheres as mais afetadas. Os autores concluíram que os níveis de estresse e de sintomas não indicaram um quadro de fadiga crítico, porém indicaram uma ação preventiva, que poderia incluir a aplicação de um programa de diagnóstico, orientação e controle do estresse (Costa et al., 2007).

Para a constituição das variáveis deste estudo utilizou-se como referência outros estudos científicos, especialmente o de Violanti (1999) que tivera o objetivo de verificar o efeito do tempo de serviço na percepção de estresse do policial. Foram testadas as hipóteses de que policiais passam por estágios transitórios em suas carreiras e que esses estágios interferem na percepção do estresse por parte dos mesmos. Participaram do estudo 500 policiais distribuídos aleatoriamente entre 21 organizações policiais na parte ocidental do estado de Nova York, EUA.

Os resultados foram consonantes com as hipóteses dos estágios de carreira definidos em quatro fases. 0 estágio de alarme: ocorre durante os primeiros cinco anos, e o comportamento pode ser equiparado ao "choque da realidade". É uma situação verificada pelo policial recém-formado de que o trabalho real de polícia é bem diferente da sua expectativa, e daquele aprendido durante o seu curso de formação. 0 estresse tenderá a crescer intensamente durante esse estágio. 0 estágio de desencanto: ocorre durante o sexto ano e continua até o meio da carreira (12-14 anos). 0 estresse ainda deve continuar a aumentar durante este estágio, porque os ideais aprendidos nos cursos de formação tornam-se cada vez mais distantes. Assim, nessa fase, os policiais tornam-se desencantados com a falta de apreciação de seu trabalho e apresentam uma sensação de fracasso pessoal, por se sentirem incapazes de lidar com as exigências do policiamento. 0 estágio de personalização: dos 14 aos 20 anos de carreira os policiais atravessam um estágio de personalização. 0 policial começa a buscar novas perspectivas e cria alternativas pessoais, em detrimento das metas de trabalho. Aqui, os policiais buscam as metas individuais e passam a não se inclinar mais para os ideais da instituição comuns no início da carreira. Essa mudança de valores pode ter um efeito decrescente no estresse. 0 estágio de introspecção: esse período após os 20 anos de serviço torna-se um tempo de reflexão para os policiais. É um período que tende a torná-los "saudosistas", 
no qual irão pensar nos primeiros anos da carreira como "os velhos bons tempos". É uma época na qual os policiais, de algum modo, encontram-se mais seguros em relação à carreira. E os níveis de estresse diminuem ainda mais (Violante, 1999).

Portanto, as variáveis que compõem este trabalho compreendem os estágios de carreira profissional correlacionados às relações interpessoais e aos níveis de estresse destes servidores. 0 objetivo foi verificar o efeito do tempo de carreira nos níveis de estresse e nas características de relacionamento interpessoal entre os policiais alunos dos cursos de formação de oficiais da Policia Militar de um estado brasileiro. É de grande valia a busca de melhores condições de trabalho e de vida dos policiais militares, como forma de se alcançar as metas definidas pela organização e a melhora da qualidade dos serviços prestados à sociedade.

\section{Metodologia}

Participantes

Participaram da pesquisa um grupo de 325 policiais, alunos dos cursos de Formação de Oficiais da Polícia Militar de um estado no Sudeste brasileiro, com idades variando entre 18 e 49 anos (M=31,9 e $\mathrm{DP}=8,3$ ), sendo $90,8 \%$ dos sujeitos do sexo masculino (297). Na data de aplicação $37,8 \%$ dos sujeitos eram solteiros (123), 56,3\% casados (183), 3,4\% divorciados (11), 2,2\% amasiados (7), 0,3\% viúvo (1). Quanto à escolaridade, $21,5 \%$ já possuíam um curso superior (70), 0,9\% com pós-graduação, enquanto para 77,6 \% o curso de formação de oficiais seria o primeiro curso superior (254). 0 tempo de serviço como policial militar variou entre 2 meses e 23,75 anos $(M=10,56$ e $\mathrm{DP}=8,54)$.

Instrumentos

Inventário de Sintomas de Stress para Adultos de Lipp (ISSL): instrumento desenvolvido para medir o nível de estresse global e não ocupacional em jovens e adultos. Foi validado em 1994 por Lipp (1994) e Guevara em populações de diferentes regiões do País e padronizado por Lipp (2000). O ISSL foi utilizado em inúmeras pesquisas e trabalhos na área do estresse no Brasil e emprega um modelo quadrifásico, com cada fase refletindo a intensidade do estresse: alerta, resistência, quase exaustão e exaustão, é composto por 37 itens de natureza somática e 19 de natureza psicológica, sendo alguns repetidos, diferenciados apenas em termos de intensidade. Esses itens são organizados em três quadros. 0 primeiro quadro (Q1) avalia a fase de alerta e inclui 12 sintomas físicos e três psicológicos. 0 participante é instruído a marcar os sintomas físicos ou psicológicos que experimentou nas últimas 24 horas. O segundo quadro (Q2) é composto de 10 sintomas físicos e cinco psicológicos; nesse quadro, o participante é instruído a marcar os sintomas que experimentou na última semana. Conforme a frequência de sintomas apontados nesse quadro é diagnosticada a fase de resistência ou quase-exaustão. Por último, o terceiro quadro (Q3) avalia a fase de exaustão e é composto por uma lista de 12 sintomas físicos e 11 psicológicos, na qual o participante é instruído a marcar aqueles que experimentou no último mês.

Check List of Interpersonal Transactions - Revised (CLOIT-R) (Kiesler, Goldston, Schimidt, 1991): trata-se de um inventário construído com a finalidade de mapear o comportamento interpessoal de pessoas alvo. Foi traduzido e adaptado por Couto van Hattum, Vandenberghe e Benfica (2005) e teve suas propriedades psicométricas e aplicações para a população brasileira investigadas por Couto, van Hattum, Campos (2006) Couto, Muniz, vandenberghe, van Hattum, (2008). Nesse estudo, foi utilizada a forma, de autoclassificação, que deve ser respondida pela pessoa alvo, e contém 96 proposições que descrevem ações que podem ocorrer em interações entre pessoas. Todas as proposições são iniciadas com a partícula Quando estou com outras pessoas... que fica centralizada no início de cada página. Os sujeitos são solicitados a ler as proposições e marcar aquelas que descrevem os tipos de interações mais característicos de sua conduta.

As proposições estão divididas nas 16 escalas bidimensionais, a saber: Dominância (A), Competição (B), Desconfiança (C), Frieza Afetiva (D), Hostilidade (E), Isolamento (F), Inibição (G), Insegurança (H), Submissão (I), Deferência (J), Confiança (K), Calor Afetivo (L), Amigabilidade (M), Sociabilidade (N), Exibicionismo (0), Segurança (P). Cada uma delas contém seis proposições que descrevem relações em dois níveis de intensidade, três proposições de intensidade moderada as quais uma marca corresponde a um ponto e três em um grau de extrema intensidade para as quais uma marca recebe dois 
pontos. 0 resultado bruto é obtido somando-se os pontos, 1 ou 2 dependendo do nível de intensidade da proposição, para cada resposta registrada pelo sujeito na folha de respostas. Cada escala pode receber um escore bruto que varia entre 0 e 9 pontos.

\section{Procedimentos de Coleta}

Nas turmas do curso de formação de oficiais, a coleta ocorreu de forma coletiva nas salas de aula e levou aproximadamente uma hora e trinta minutos. Foi solicitado ao professor que disponibilizasse o tempo de aula para os procedimentos da pesquisa. Os alunos foram convidados a participar da pesquisa, esclarecidos quanto aos procedimentos e ao caráter voluntário de sua participação. Aqueles que concordaram em participar assinaram o Termo de Consentimento Livre e Esclarecido e foram orientados a responder ao teste ISSL. Em seguida, ao terminarem de responder ao ISSL, os alunos receberam o caderno de autoclassificação do CLOIT-R.

\section{Procedimentos de Análise}

Ao fim das aplicações, os testes foram corrigidos, e os resultados dos protocolos foram tabulados no programa SPSS versão 15.0 for Windows. Foram estimadas as estatísticas descritivas das respostas dos sujeitos ao ISSL e em seguida ao CLOIT-R. A amostra foi dividida em grupos conforme o tempo de carreira policial, e os resultados dos níveis de estresse e das características de interações interpessoais foram comparados por meios das técnicas estatísticas $T$ de student e ANOVA oneway e selecionado como teste pos hoc o Tukey HSD e comparada a significância das diferenças de média entre os quatro grupos de estágio profissional.

A pesquisa foi conduzida respeitando os padrões exigidos pela declaração de Helsinque. Em princípio, o projeto foi encaminhado ao Comitê de Ética da Academia de Polícia Militar do Estado em que se realizou a pesquisa, foi analisado e consentida sua implementação.

\section{Resultados e discussão}

Com a finalidade de alcançar o objetivo do presente estudo, em princípio procedeu-se a estimação dos níveis de estresse e dos tipos de sintomas mais frequentes na amostra. Os resultados com relação ao estresse, de acordo com o critério Q1 (frequência maior que seis sintomas declarados nas últimas 24h) que designa a fase de alerta, mostraram uma variação entre zero e 11,0 com (M = 2,33 e DP = 2,14) apenas 5,5\% dos sujeitos da amostra apresentaram sinais de estresse $(\mathrm{N}=18)$. Conforme o critério Q2 (frequência de sintomas declarados na última semana superior a 3) que designa a fase de resistência e quase-exaustão, os resultados variaram entre zero e $14,0(M=3,39$ e $D P=2,71)$ sendo que $41,8 \%$ dos sujeitos apresentaram sinais de estresse $(\mathrm{N}=136)$. E de acordo com o critério Q3(frequência de sintomas superior a 8 no último mês) que designa a fase de exaustão, os resultados variaram entre zero e $17,0(M=3,28$ e $D P=3,29)$ sendo que $8,6 \%$ dos sujeitos apresentaram sinais de estresse $(\mathrm{N}=28)$.

Entre os sintomas relatados, houve uma predominância de sintomas físicos assinalados no inventário em relação aos sintomas psicológicos. Os sintomas físicos variaram entre zero e $25(\mathrm{M}=5,00$ $\mathrm{DP}=4,28$ ) sendo que as queixas mais frequentes foram sensações de desgaste físico constante (55\%), cansaço constante $(46,8 \%)$, problemas com a memória $(39,8 \%)$, tensão muscular $(37,9 \%)$ e insônia $(25,1 \%)$. Enquanto que os sintomas psicológicos variaram entre zero e $17(\mathrm{M}=4,00 \mathrm{DP}=3,61)$ e as queixas mais frequentes foram, cansaço excessivo $(44,3 \%)$, pensar constantemente em um só assunto $(38,8 \%)$, irritabilidade excessiva $(33,3 \%)$, perda do senso de humor (33,3\%), angústia/ansiedade diárias (33\%).

Os resultados indicam que, em primeiro lugar, o número de policiais que apresentaram sinais de estresse é preocupante $(55,9 \%)$, ou seja, mais da metade da amostra. Especialmente o grupo que apresentou sintomas característicos da fase de resistência e quase-exaustão (41,8\%), nessa fase a eliminação do estressor, ou a aplicação de técnicas de controle tem efeito positivo na recuperação do organismo e na interrupção do processo. Pelo contrário, se a exposição ao estressor se prolongar e não houver uma adaptação do organismo, o sistema imunológico pode ser comprometido (Costa et al., 2007). Em segundo lugar, os níveis de estresse encontrados apesar de não estarem impactando negativamente a vida acadêmica dos alunos, uma vez que todos eles mantinham notas acima da média, frequência às aulas adequadas e não possuíam ocorrências disciplinares, apontam para o 
desgaste do organismo diante do excesso de atividades. Os alunos dos cursos de formação de oficiais, além de responderem as exigências acadêmicas do curso, com aulas pela manhã e à tarde, ainda devem cumprir empenhos operacionais e escalas de serviço.

Os resultados são consonantes com os da pesquisa de Andrade Souza e Minayo (2009) realizada com policiais civis revelou que a sobrecarga de trabalho também representa entre esses servidores um fator estressante relevante, com alta porcentagem das respostas. Entretanto, diante de situações de estresse, a maioria dos policiais do estudo utilizam do manejo dos sintomas, como autocontrole, apoio da família, lazer, prática de exercícios, apoio na religião e atitude positiva, seguido de significativa expressão da preferência por estratégias de esquiva, como separando-se da vida social do trabalho e isolando-se.

As pesquisas, como esta, indicam caminhos para atender as demandas de como conduzir o estresse entre esses profissionais. Em específico ao presente estudo, há indicativo de medidas de promoção da saúde, no sentido de auxiliar no controle adequado ao estresse visando melhorar a qualidade de vida dos alunos, evitando sofrimento desnecessário. Além de providenciar mecanismos para interromper o ciclo do estresse e evitar a suscetibilidade dos policiais às doenças.

0 próximo passo foi explorar a relação entre a frequência de sintomas de estresse e o tempo de carreira do policial. Desta forma, a amostra foi dividida em grupos por tempo de carreira conforme os critério do estudo de Violanti (1999).

Assim, 143 sujeitos, 44\% da amostra foram classificados no estágio um; 37 sujeitos $(11,4 \%)$ foram classificados no estágio dois; 50 sujeitos $(15,4 \%)$ classificados no estágio três; e $95(29,2 \%)$ no estágio quatro.

Quando são consideradas as médias dos sintomas de estresse relatados pelos participantes ao longo dos grupos de estágios profissionais, o que se pôde observar nas curvas apresentadas na Figura 1 é uma queda sistemática dos sintomas percebidos na última semana e no último mês. Com relação aos sintomas percebidos nas últimas $24 \mathrm{~h}$ pôde-se notar uma oscilação entre declive, aclive e novo declive, porém as maiores médias permanecem com o grupo de primeiro estágio profissional.

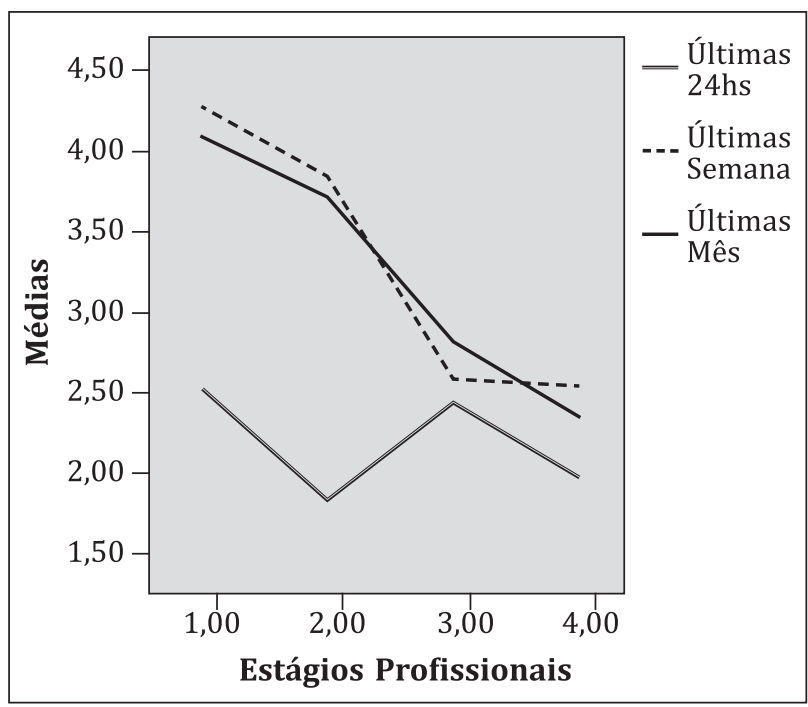

Figura 1 - Médias de sintomas de estresse entre estágios profissionais dos policiais militares, 2009.

Fonte: Dados da pesquisa.

Esses resultados sugerem a interpretação de que quanto mais experientes os policiais se tornam, menos susceptíveis eles são ao estresse. Para verificar a plausibilidade dessa interpretação, foi comparada a significância das diferenças de média entre os quatro grupos de estágio profissional. Os resultados encontrados para as diferenças observadas com relação aos sintomas percebidos na última semana foi $[F(1,324)=8,50 ; p<0,000]$, indicando que são significativas. Da forma semelhante, o resultado para as diferenças, entre o primeiro e o último estágio profissional, dos sintomas percebidos no último mês foi $[F(1,324)=4,92 ; p<0,002]$, indicando que a probabilidade de ocorrência ao acaso é insignificante.

Ao contrário, quando são examinadas as diferenças de média dos sintomas percebidos nas últimas $24 \mathrm{~h}$ entre os quatro grupos de estágio profissional nenhuma delas é significativa. Dessa forma, os resultados sugerem que a experiência profissional, medida em tempo de carreira, torna os sujeitos menos susceptíveis a estresse prolongado, porém não afetando a sensibilidade a estressores imediatos.

Os resultados encontrados por Violanti (1999) mostraram que os níveis de estresse tendem a cair depois do segundo estágio profissional, porém, no presente estudo, os níveis de estresse tendem a cair já no segundo estágio profissional. Algumas ressalvas devem ser feitas, pois o autor utilizou uma amostra de policiais que desempenhavam suas funções em tempo integral ao passo que no presente 
estudo os policiais foram recrutados no período de estudo e formação estando frequentando um curso de progressão na carreira e suas atividades de policia são compatibilizadas com as atividades de alunos. Contudo as atividades de alunos de curso de formação impõem aos sujeitos estresses novos, relacionados com o desempenho acadêmico, que estão diretamente relacionados com a promoção futura desses policiais, como também a possibilidade de escolha da localidade em que vão servir depois de formados.

Outra condição que corrobora com este achado foi pesquisada como um dos principais fatores de risco de sofrer violências, uma vez que a agressão, sofrida ou assistida, foi considerada determinante do estresse na prática policial. Assim, revelou-se que entre policiais militares o tempo de serviço foi um fator relevante, e que policiais com menos tempo de serviço, isto é, com até dez anos de profissão, correm 2,4 mais riscos no trabalho policial do que os veteranos (Minayo et al., 2007)

Seguindo os objetivos do presente trabalho, o próximo passo foi estimar as características de relações interpessoais mais frequentes entre os policiais e verificar qual o efeito do tempo de carreira na qualidade dessas interações interpessoais.

Tabela 1 - Estatísticas descritivas dos sujeitos nas 16 escalas do CLOIT-R. Brasil, 2009

\begin{tabular}{lccccc}
\hline & N & Mínimo & Máximo & Média & $\begin{array}{c}\text { Desvio } \\
\text { Padrão }\end{array}$ \\
\hline Dominância & 325 & 0 & 9,00 & 2,97 & 1,85 \\
\hline Competição & 325 & 0 & 6,00 & 1,68 & 1,11 \\
\hline Desconfiança & 325 & 0 & 8,00 & 1,58 & 1,62 \\
\hline Frieza Afetiva & 325 & 0 & 8,00 & $\mathbf{0 , 9 3}$ & 1,25 \\
\hline Hostilidade & 325 & 0 & 8,00 & $\mathbf{1 , 0 3}$ & 1,56 \\
\hline Isolamento & 325 & 0 & 8,00 & $\mathbf{0 , 8 2}$ & 1,46 \\
\hline Inibição & 325 & 0 & 9,00 & 2,47 & 2,18 \\
\hline Insegurança & 325 & 0 & 7,00 & 2,07 & 1,71 \\
\hline Submissão & 325 & 0 & 9,00 & 1,23 & 1,77 \\
\hline Deferência & 325 & 0 & 9,00 & 3,40 & 1,99 \\
\hline Confiança & 325 & 0 & 9,00 & $\mathbf{3 , 6 6}$ & 2,01 \\
\hline Calor Afetivo & 325 & 0 & 9,00 & $\mathbf{4 , 0 0}$ & 2,04 \\
\hline Amigabilidade & 325 & 0 & 9,00 & $\mathbf{5 , 5 9}$ & 2,30 \\
\hline Sociabilidade & 325 & 0 & 9,00 & 3,35 & 1,81 \\
\hline Exibicionismo & 325 & 0 & 9,00 & 1,50 & 1,90 \\
\hline Segurança & 325 & 0 & 9,00 & 3,16 & 1,93 \\
\hline N Válido & 325 & & & & \\
\hline
\end{tabular}

Fonte: Dados da pesquisa.
Os resultados apontados na Tabela 1 apresentam as médias de respostas por padrões de relacionamento e indicam que os participantes percebem suas relações como mais amigáveis, calorosas e confiantes. Estas características são comuns em sujeitos que percebem suas relações orientadas por uma prontidão em cooperar com as pessoas com quem estão interagindo, são corteses e atenciosos. Também, são rápidos em expressar cordialidade e são compreensivos com os sentimentos delas. Outra característica frequente é a confiança, caracterizando pessoas honestas sobre suas intenções ou motivos e que confiam nas observações das pessoas sobre suas próprias intenções e motivos.

Ao lado disso, as escalas com a menor média de respostas são aquelas que caracterizam relações que tendem ao isolamento, frias e hostis. Não por acaso dois dos padrões de interações interpessoais menos escolhidos são polos opostos das escalas mais frequentes, Hostilidade vs Amigabilidade, Frieza Afetiva vs Calor Afetivo. Altas pontuações nas três escalas caracterizariam sujeitos que protegem sua privacidade das pessoas com quem estão interagindo, mantêmse distantes, não se interessam pelas ocupações pessoais delas ou parecem querer retirarse da sua presença para seguir suas atividades solitárias. Também encontram dificuldade em expressar cordialidade e têm pouca simpatia a respeito do comportamento irregular delas. É frequente encontrar sujeitos que por vezes violam o espaço das pessoas e recusam-se a cooperar com elas.

Muitas vezes os próprios profissionais policiais consideram que, para exercerem a sua prática, há a necessidade de se destituir de capacidades inerentes ao ser humano, como pensar, sentir, experimentar inseguranças e medos. Aprenderem a atuarem como 'máquinas' faz parte até mesmo do processo de formação desses servidores (Silva \& Vieira, 2008).

Seguindo a linha geral de análise, conforme realizado com os níveis de estresse, verificou-se como tais padrões de interação interpessoal apareciam ao longo dos estágios profissionais. Desta forma, os resultados ilustrados pela Figura 2 mostram que as médias das escalas que representam relações interpessoais (RI) positivas e socialmente desejáveis apresentam um considerável aumento 
de frequência no último estágio profissional em relação ao primeiro. Quando são consideradas as escalas que refletem padrões de relacionamento interpessoal negativos ou socialmente pouco reforçadoras, observa-se uma queda das médias do primeiro para o último estágio em frieza e hostilidade. Um pouco diferente, é a escala de isolamento que apresenta um leve aumento do primeiro para o último estágio, caracterizando que o policial mais experiente percebe-se levemente afastado das situações sociais.

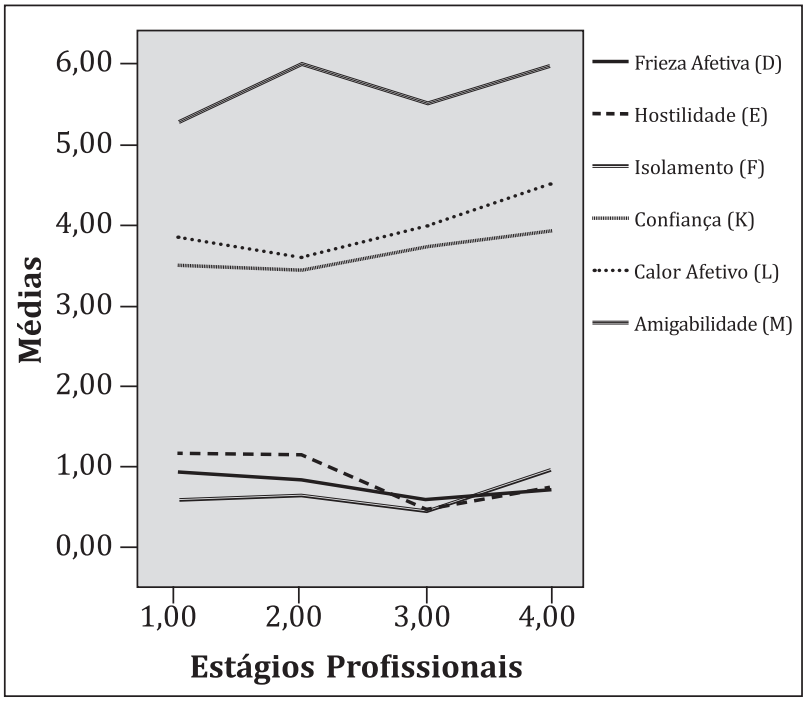

Figura 2 - Comparação entre escalas RI positivo entre estágios profissionais dos policiais militares. Brasil, 2009

Fonte: Dados da pesquisa.

Esse resultado sugere que os padrões de interações interpessoais dos policiais tendem a melhorar de acordo com sua experiência profissional, apesar de tornarem-se mais afastados do convívio social. Com o intuito de explorar essa interpretação e verificar a probabilidade da diferença de média, nas escalas, entre o primeiro e o último estágio profissional ter ocorrido ao acaso, foi realizado um teste $t$ comparando as médias. Os resultados apontaram que, nas escalas de Amigabilidade $[\mathrm{T}(1,94)=2,83 ; \mathrm{p}<0,006] \mathrm{e}$ Calor afetivo $[\mathrm{T}(1,94)=3,03 ; \mathrm{p}<0,003]$, as diferenças são significativas, e na escala de Confiança $[\mathrm{T}(1,94)=1,79 ; \mathrm{p}<0,07]$ o resultado é marginalmente significativo. Assim como, nas escalas de Hostilidade $[T(1,94)=-3,14 ; p<0,002]$ e Isolamento $[T(1,94)=2,05 ; p<0,04]$, os resultados apontaram que as diferenças são significativas. Porém, na Frieza Afetiva, a diferença encontrada não foi significativa. Os resultados do teste $t$ reforçam a interpretação proposta de melhora da qualidade percebida das relações interpessoais com a experiência profissional.

A partir dos resultados dessa pesquisa, podemos inferir que, ao longo da carreira profissional do policial, há indícios fortes de que medidas para lidar com o estresse são necessárias visando à melhoria da qualidade de vida, que consequentemente irá refletir na segurança da população. Mas é o início da carreira do policial que requer uma atenção especial, tanto quanto a percepção dos níveis de estresse quanto da qualidade das relações interpessoais.

Estes dados devem ser considerados pela gestão do serviço e na formulação de política pública que ampare a formação continuada do servidor. Bezerra e Neves (2010) concluem que pesquisas que forneçam evidências quanto ao campo de saúde do trabalhador têm potencial efetivo sobre as políticas e ações de saúde, mobilizando transformação das relações saúde-ambiente-trabalho no sentido de constituir segurança aos trabalhadores.

No entanto, no estudo de Andrade et al. (2009), que se motivou pela raridade de estudos da área da segurança pública e de propostas de intervenção e avaliação centradas no profissional, operacionalizou ações visando autoestima e qualidade de vida de policiais civis no Rio de Janeiro. Os resultados foram tão promissores que, no processo de avaliação proposto pelos pesquisadores, $78 \%$ dos participantes relataram que a intervenção contribuiu tanto para a vida pessoal quanto profissional, no sentido de aprender a conduzir as adversidades, trabalhar em equipe, a refletir quanto a qualidade de vida e redução do estresse por meio do relaxamento e humor. Diante desta avaliação, muitos sugeriram que tais ações constituam o processo de formação dos policiais.

\section{Considerações finais}

Ao proceder a análise dos resultados, pode-se verificar que os níveis de estresse apresentados pelos alunos dos Cursos de Formação de Oficiais de uma Polícia Militar do Sudeste brasileiro, apesar de não serem críticos, porque a maior frequência de sintomas ocorre na última semana (Fase de resistência/quase-exaustão) e apenas uma pequena porcentagem de alunos satisfaz os critérios para 
presença de estresse pelos critérios do Q1 e Q3, indicam a necessidade de introdução de medidas de controle e manipulação de estressores para proteger os futuros oficiais de danos na sua saúde ocasionados por estresse. Outro aspecto importante que foi verificado é que os sintomas de estresse diminuem sistematicamente conforme o tempo de carreira aumente, esse resultado repete parcialmente os resultados de Violanti (1999), visto que se tomou este estudo como referência na constituição das variáveis pesquisadas.

Algumas deficiências com relação ao presente estudo dizem respeito ao método ser transversal, não permitindo observações mais detalhadas sobre a ocorrência das variáveis estudadas e mesmo a demonstração efetiva da progressão ou regressão dos efeitos ao longo dos estágios de carreira. Apesar de a amostra se constituir de quase todo o efetivo de policiais em curso de formação de oficiais, a sua distribuição nos respectivos grupos foi desigual apresentando estágios profissionais com menor número de policiais como foi o caso do estágio dois, talvez uma possível investigação a ser feita no futuro considere uma divisão por ano de curso o que pode garantir uma distribuição igualitária e também um controle maior sobre os intervalos temporais na carreira policial. Outro aspecto digno de nota é que o fato de estarem em curso e avaliados diuturnamente pode ter contribuído com um aumento da influência de desejabilidade social, elemento comumente conhecido nos resultados de instrumentos de autorrelato, nas respostas dadas aos itens das escalas.

De todo modo, os resultados podem ser considerados descrições razoáveis dos eventos estudados e aconselha-se que novos estudos sejam desenvolvidos na tentativa de replicar esses resultados. Também a utilização de métodos diferentes que permitam a triangulação de métodos para melhorar as observações sobre as dimensões psicológicas estudadas.

\section{Referências}

Andrade, E. R., Sousa, E. R., \& Minayo, M. C. S. (2009). Intervenção visando à autoestima e qualidade de vida dos policiais civis do Rio de Janeiro. Ciência \& Saúde Coletiva, 14(1), 275-285.
Bezerra, M. L. S., \& Neves, E. B. (2010). Perfil da produção científica em saúde do trabalhador. Saúde e Sociedade, 19(2), 384-394.

Brito, D. P., \& Goulart, I. B. (2005). Avaliação psicológica e prognóstico de comportamento desviante numa corporação militar. Psico-USF, 10(2), 149-160.

Costa, M., Accioly, Jr. H., Oliveira, J., \& Maia, E. (2007). Estresse: Diagnóstico dos policiais militares em uma cidade brasileira. Rev Panam Salud Publica, 21(4), 217-222.

Couto, G., Van Hattum, A. C. F. M. V., Vandenberghe, L. M. A., \& Benfica, E. (2005). Tradução, análise semântica e adaptação do check list of interpersonal transactions - revisado. Avaliação Psicológica, 4 (1), 45-47.

Couto, G., Vandenberghe. L., Van Hattum, A. C., \& Campos, H. R. (2006). Propriedades psicométricas do checklist de relações interpessoais - Revisado. Psicologia Argumento, 24(47), 15-28.

Couto, G., Muniz, M., Vandenberghe, L., \& Van Hattum, A. C. (2008). Diferenças relacionadas ao sexo observadas no checklist de relações interpessoais - Revisado. Avaliação Psicologica, 7(3), 347-357.

Dela Coleta, A. S. M., \& Dela Coleta, M. F. (2008). Fatores de estresse ocupacional e coping entre policiais civis. Psico-USF, 13(1), 59-68.

Kiesler, D. J., Goldston, C. S., \& Schmidt, J. A. (1991). Manual for Check List of Interpersonal Transactions: Revised and Check List of Psychoterapy Transactions - Revised. Virginia: Virginia Commonwealth University.

Lipp, M. N., \& Guevara, A. J. H. (1994). Validação empírica do inventário de sintomas de stress. Estudos de Psicologia, 11(3), 43-49.

Lipp, M. N. (1996). Stress: Conceitos básicos. In Lipp M. N. (Org.). Pesquisas sobre stress no Brasil: Saúde, ocupações e grupos de risco (pp. 17-31). Campinas: Papirus.

Lipp, M. N. (2000). Manual do inventário de stress para adultos de Lipp (I.S.S.L). São Paulo: Casa do Psicólogo. 
Minayo, M. C. S., \& Souza, E. R. (2003). Missão investigar: Entre o ideal e a realidade de ser policial. Rio de Janeiro: Garamond.

Minayo, M. C. S., Souza, E. R., \& Constantino, P. (2007). Riscos percebidos e vitimização de policiais civis e militares na (in)segurança pública. Caderno Saúde Pública, 23(11), 2767-2779.

Silva, M. B., \& Vieira, S. B. (2008). O processo de trabalho do militar estadual e a saúde mental. Saúde e Sociedade, 17(14), 161-170.

Silveira, N. M., Vasconcelos, S. J. L., Cruz, L. P., Kiles, R. F., Silva, T. P., Castilhos, D. G., et al. (2005). Avaliação de Burnout em uma amostra de policiais civis. Revista de Psiquiatria do Rio Grande do Sul, 27(2), 159-163.

Souza, E. R. S., Franco, L. G., Meireles, C. C., Ferreira, V. T., \& Santos, N. C. (2007). Sofrimento psíquico entre policiais civis: Uma análise sob a ótica de gênero. Caderno Saúde Pública, Rio de Janeiro, 23(1), 105-114.
Violanti, J. M. (1999). Padrões de estresse no trabalho policial: Um estudo longitudinal. Revista Unidade - Revista de Assuntos Técnicos da Polícia Militar, 21(37), 19-27.

Organização das Nações Unidas (ONU). VIII Congresso das Nações Unidas para a Prevenção do Crime e o Tratamento dos Delinquentes. Princípios orientadores para a prevenção e repressão do crime organizado. 1990. Recuperado em 12 dez. 2010, em http://www.direitoshumanos.usp.br/documentos/ onu/prevencaocrime.html

Ornstein, R. (1998). A mente certa: Entendendo o funcionamento dos hemisférios. Rio de Janeiro: Campus. 